University of Nebraska - Lincoln

DigitalCommons@University of Nebraska - Lincoln

Congreso internacional sobre iconografía

precolombina, Barcelona 2019. Actas.

8-20-2020

\title{
Iconografía prehispánica en entornos virtuales: The Age of Empires II
}

Natalia Moragas Segura

Manuel J. González Manrique

Follow this and additional works at: https://digitalcommons.unl.edu/actas2019

Part of the American Material Culture Commons, Indigenous Studies Commons, Museum Studies Commons, Other History of Art, Architecture, and Archaeology Commons, and the Other Languages, Societies, and Cultures Commons

This Article is brought to you for free and open access by the Zea E-Books at DigitalCommons@University of Nebraska - Lincoln. It has been accepted for inclusion in Congreso internacional sobre iconografía precolombina, Barcelona 2019. Actas. by an authorized administrator of DigitalCommons@University of Nebraska - Lincoln. 


\section{Iconografía prehispánica en entornos virtuales: The Age of Empires II}

\author{
Natalia Moragas Segura \\ Universidad de Barcelona, España \\ nataliamoragas@ub.edu
}

\author{
Manuel J. González Manrique \\ Universidad Autónoma del Estado de Hidalgo, México \\ mjgman@gmail.com
}

\section{Introducción}

El hecho de contar historias es una necesidad intrínseca de las sociedades. Relatar hazañas, ciertas o no, es parte de nuestra naturaleza, alrededor de una fogata o recreando las mismas en una pantalla de alta resolución, pero necesitamos de las historias. Dentro de la producción literaria no cabe duda que las historias con fondo realista cautivan con mayor fervor al consumidor, pues le acercan a sí mismo, "me pudo pasar a mí" se repite, y así, la base "histórica" va a estar en todas las grandes narraciones, La Ilíada, La Divina Comedia, el Popol Wuj o El Quijote.

Los medios actuales han absorvido este conocimiento narrativo milenario y hoy nos encontramos con una gran producción de novelas con base histórica, ambientadas o muy documentadas en hechos determinados. El cine, por su parte, tiene una larga tradición de representaciones de períodos históricos que se remonta a su nacimiento; la televisión succionó del cine el lenguaje y pronto lo hizo suyo, aprovechando el hecho verídico como un juez que certifica que lo que se va a contar está pasando o está "basado en hechos reales"; y los videojuegos, esa industria que todo el mundo relaciona con lo lúdico y nadie le presta atención, se ha multiplicado desde aquel insulso pero entretenido Pong a 
narrativas multijugador y de mundos infinitos donde se puede recrear la historia con mayor certera y hacernos partícipes de ella por la propia naturaleza del producto, la interactividad.

Ya en los noventa Robert Rosenston (1997) se atrevía a decir que, con cierto ajuste lingüístico, de lo textual a lo audiovisual, la metodología que utilizábamos para realizar un texto académico podía hacerse con imágenes en movimiento, o sea, con el cine. Su atrevimiento se sustentaba en que finalmente la producción literaria histórica y la audiovisual eran las mismas, el procedimiento de ambos oficios eran idénticos; recopilar información, analizarla, interpretarla, y realizar un texto, ¿qué diferencia había entonces entre el resultado del producto fuese en papel o en un medio audiovisual? Evidentemente sólo el lenguaje y la forma de leerlo, que no es poco.

Los videojuegos nunca han tenido una pretensión académica, pero factores como el mercado, la comunicación inmediata que proporciona internet entre el creador y el consumidor, las demandas del comprador y, evidentemente, los avances técnicos en el ámbito de la computación han hecho que el videojuego, por motu proprio, inicie un camino de profesionalización que hace que las narrativas donde la historia es un elemento más de creación e imaginación hayan llegado a límites de perfección al representar un pretérito distinto, que hoy día, con ellos, podemos explicar un contexto específico.

Su consumo masivo en múltiples dispositivos nos pone ante una realidad innegable, una de las formas de difusión de la historia más potentes y extendidas está en nuestros bolsillos, es el videojuego y eso nos debe introducir al debate de su creación y uso.

Este trabajo reflexiona sobre la potencialidad del videojuego a la hora de exponer al público masivo y global una determinada cultura. En nuestro caso nos centraremos en la cultura azteca, ya que la inmensa mayoría de los videojuegos se centran en unas pocas culturas muy atractivas para el público, como son la egipcia o la romana. Civilizaciones tan importantes en la historia universal como la mexica, la maya o la inca llegan en una segunda remesa de videojuegos, al igual que lo hizo a la historiografía, y su presencia es escasa.

El videojuego que analizaremos en profundidad es el Age of Empires II en su extensión The Conqueror, ya que se trata del primer videojuego que incluye culturas prehispánicas y en sus campañas puedes revivir momentos determinados de la historia de estas civilizaciones, concretamente la forma de representación de la campaña de Moctezuma. Esto está unido a que en la década de los noventa se va a inaugurar una nueva generación de videojuegos de estrategia en tiempo real (RTS por sus siglas en inglés) donde la potencialidad de la inteligencia artificial (AI) (Bettner, P., \& Terrano, M., 2001: 30) y la gran variedad de características y particularidades de las unidades intentaban aproximarse, con herramientas nunca antes vistas, a la cultura representada.

Es por esta razón por la que partimos de un estudio de representación donde la iconografía está presente de forma constante, y entre las dos líneas iniciales del estudio del videojuego, la ludología y la narratología nos decantamos por esta última, ya que es la forma de contar la historia uno de los factores a analizar en este trabajo. Dentro de este marco, nuestra preocupación es estética y massmediática debido a la generalización y repetición de modelos que generan estereotipos que, en muchos casos, están muy lejos de la cultura que se intenta representar.

Como docentes universitarios no podemos descuidar la cuestión educativa, pues casi superados los fantasmas sobre las nuevas tecnologías se observa la utilidad del videojuego para la enseñanza a todos los niveles académicos y sociales.

\section{Estado del arte}

Los estudios sobre los juegos son considerablemente recientes. Las nuevas puertas que abrieron los Annales permitieron indagar en un mudo, habitualmente relacionado con la niñez y la infancia, que estaba mínimamente esbozado. El juego había sido básico en la vida de cualquier ser viviente, pero no se había teorizado y sistematizado su estudio. Johan Huizinga (2007) sorprendió en 1938 con su obra "Homo Ludens" inaugurando la ludología.

Huizinga estudia el juego como parte inherente del ser humano, planteando la esencia y naturaleza del mismo pero centrándose en el hecho de "jugar por jugar". Su esquema resultaba demasiado vacío para otros contenidos que no fuesen la mecánica del juego; pero muchos juegos, aunque de forma simbólica (los naipes, del dominó, la oca) plantean narrativas, historias que determinan los avances del mismo; otros, como el ajedrez, plantean una narrativa simbólica más explícita, y es del ajedrez de donde van a nacer los videojuegos por turnos que la tecnología y la creatividad convirtieron en videojuegos de estrategia en tiempo real.

De esta falta de atención a la historia nace la narratología. Tzvetan Todorov (1970) a finales de los 60 y utilizando el Decamerón, va a incidir en el estudio de las 


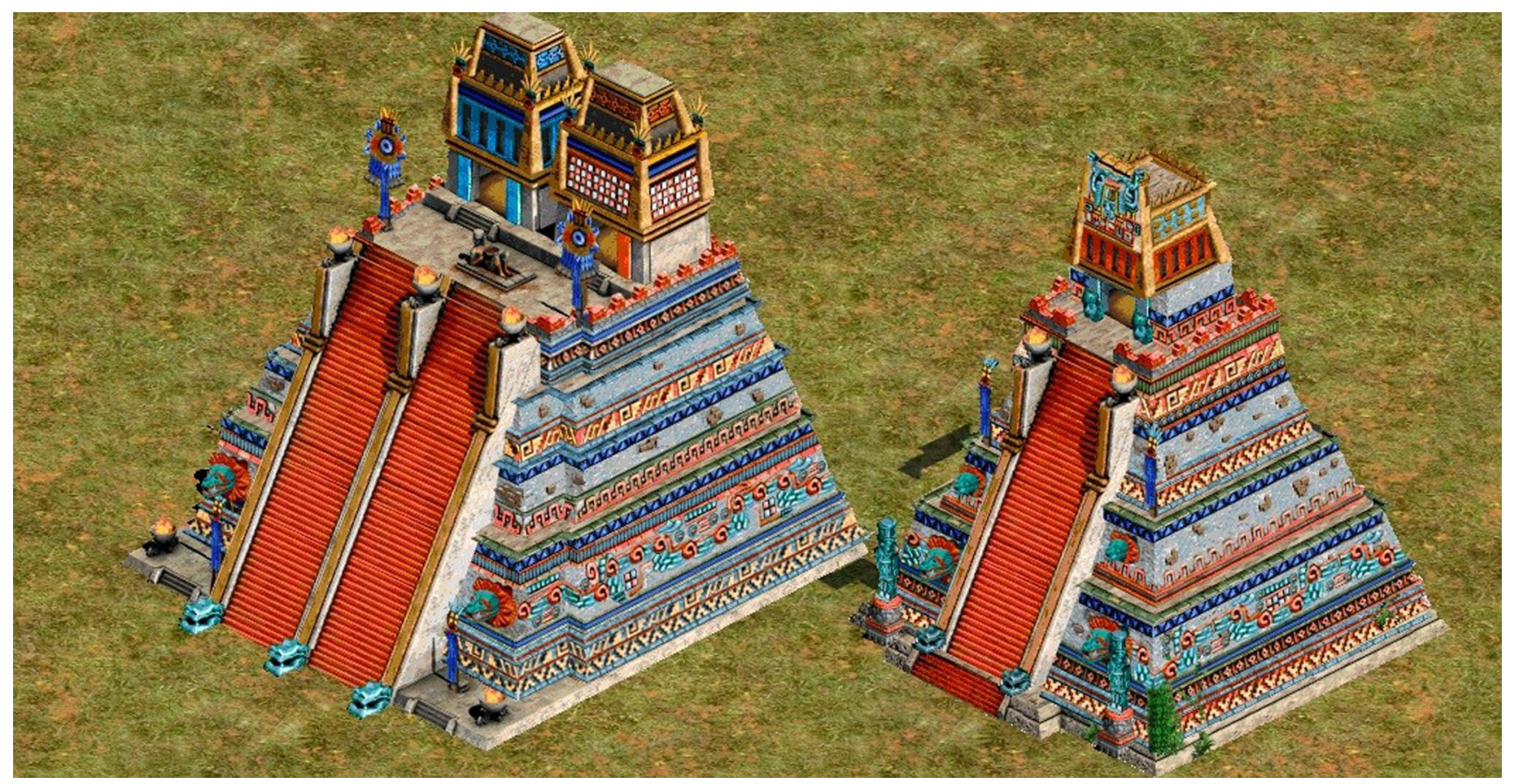

Ilustración 1 Modificación de los usuarios de los templos aztecas

relaciones entre los personajes y los "predicados base" que se pueden producir según sus características —en cierto modo la inteligencia artificial de los videojuegos se basa en estas posibles acciones que puede hacer un grupo o civilización según sus características y las circunstancias que le rodean-, a lo que se le unió el análisis de los personajes según el modelo actancial de A. J. Greimas (1971), el microuniverso narrativo y su concepto de actante como ente cuya participación en la narración es la base de su modelo actancial.

Esta propuesta nos lleva a poder analizar desde un punto de vista multidisciplinar (Frasca, G., 1999) , donde la semiótica es aliada de la iconografía y esta de la arqueología con lo que podemos explicar con perspectivas diversas la representación actual las culturas mesoamericanas.

Realmente, las bases de los videojuegos de estrategia en tiempo real tienen los mismos elementos que un hecho histórico, las relaciones de acción entre narrador, personajes, espacio y tiempo.

Uno de los debates más enfervorecidos que podemos encontrar en los foros especializados y como infalible fórmula de ataque a los videojuegos es la alteración del pasado (Jiménez Alcázar, 2018). Ciertamente muchos productos de entretenimiento - películas, novelas, series de televisión, cómic...- han jugado con un pasado posible del que se hubiese gestado una situación mundial completamente diferente a la actual base democrática occidental - totalitarismos, invasiones extraterrestres, conspiraciones y demás posibilidades distópicas. Si bien la historiografía hispana no es muy dada a que los académicos jueguen con la historia, la historia contrafactual está bastante extendida en el mundo francés y anglosajón, lo cual no ha llevado a pocos debates y críticas. Para Evans en su ensayo sobre el particular la historia contrafactual ésta se define como "un cambio en la cadena de acontecimientos que lleva a una serie de nuevos cambios que parecen seguirse de él como mínimo con algún grado de plausibilidad"(Evans, R. J., 2018), y la enfrenta a la historia paralela, o la historia que sucede dentro de otra historia, base de los videojuegos de estrategia en tiempo real o de mundo abierto.

Lo que no ha tenido en cuenta Evans en su crítica a la historia contrafactual es el potencial didáctico que posee esta narración como herramienta didáctica para la enseñanza de la historia. El discurso ucrónico aunque para él es un mero producto del contexto actual de falta de horizontes, y donde el mundo se encuentra en una constante "sensación de desorientación y miedo ante amenazas" (Evans, 2018: 53) ha sido contestado por Ferguson ya que "imaginar contrafactuales de este tipo forma parte esencial de nuestra manera de aprender" (Ferguson, 1998: 14), y la potencialidad del videojuego debido a la interactividad y a la reciente realidad virtual lo hace imbatible. 


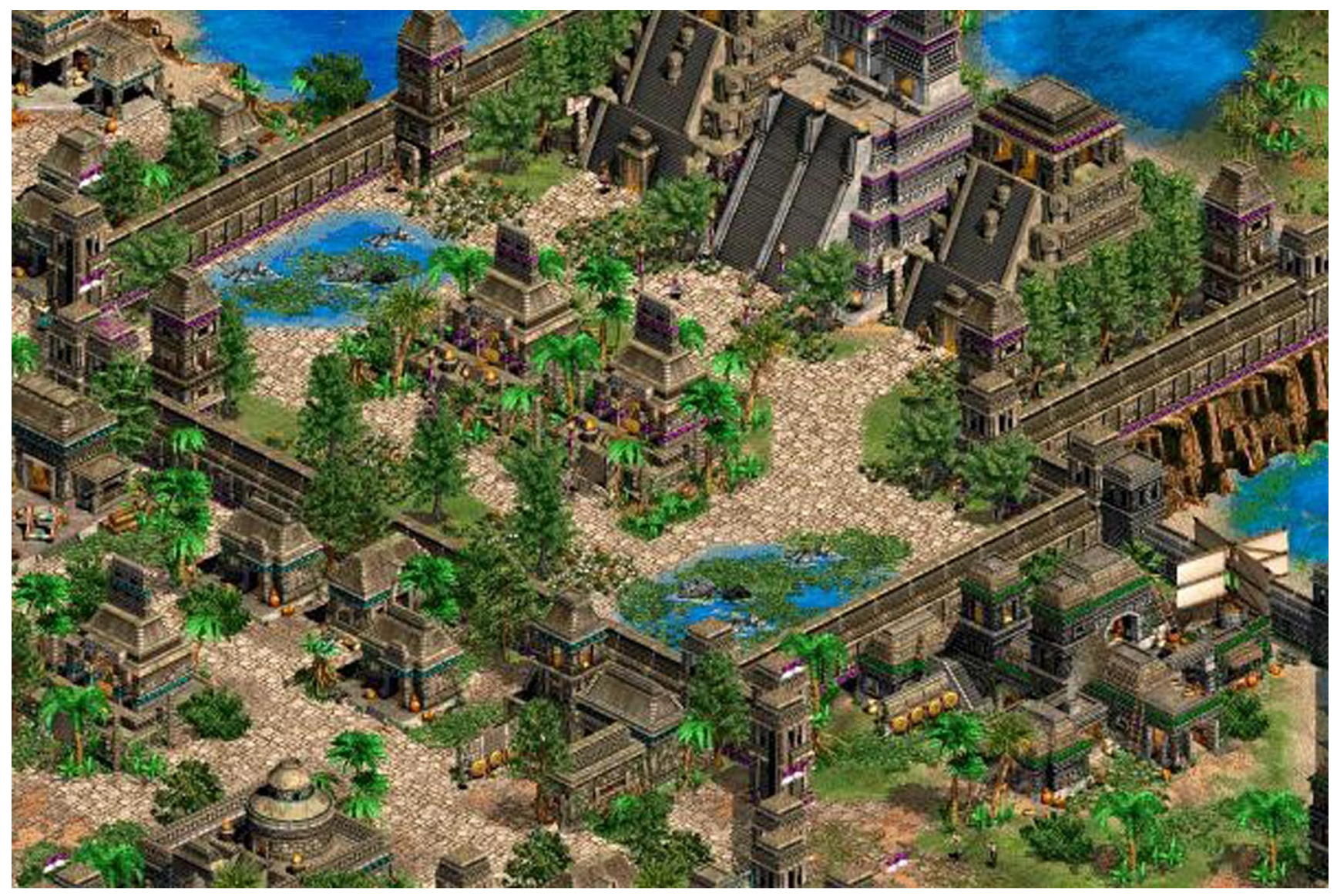

Ilustración 2 Panorámica de Tenochtitlán. En esta imagen construida por el jugador se incorporan elementos arquitectónicos y urbanísticos mixtos. Por un lado la idea del templo doble (que no especifica en la narrativa porqué) sacado de la imagen de las crónicas del Templo Mayor, decoraciones de crestería en algunos templos que corresponden a modelos de Tikal por citar un ejemplo. También la idea de las murallas que no corresponde a la tradición mayoritaria del urbanismo mesoameriacano.

Como todos los medios expresivos, el videojuego se inició como experimento completamente encorsetado a una tecnología computacional que poco podía ofrecer desde un punto de vista narrativo, pero fue esta, la narrativa, la quedióel empuje a la industria. Videojuegos como Monkey Island (LucasArts, 1990), por nombrar una aventura gráfica clásica, o Dune II (Westwood Studios, 1992) dieron alas a los desarrolladores, iniciando un proceso que ya no implicaba la adaptación de una novela o una película en aventuras conversacionales o arcades, sino que se comienzan a realizar guiones confeccionados ex profeso para la narración a través del videojuego y su naturaleza cambiante. En este momento de los años noventa es donde comienza una difusión masiva de este medio debido sobre todo a la expansión del PC y el éxito del videojuego de contenido histórico radica directamente en las posibilidades que le permite el uso libre y despreocupado de la ucronía.En palabras de Jiménez Alcázar (2018), el "fenómeno radica en la posibilidad de manipular y jugar con el pasado, según la preferencia del videojugador, usuario que puede tener o no conocimientos previos de historia".

Pero un camino diferente es el de los videojuegos que siguen un guion histórico más o menos riguroso y lo que pretenden es plantear hechos del pasado para experimentar situaciones de juego. La Campaña de Moctezuma de la expansión The Conqueror del Age of Empires II (Ensemble Studios, 1997) no juega con ucronías ni da lugar a distopías o utopías. Este videojuego relata los hechos por capítulos según la historia más extendida, y permite que juegues los momentos clave de la historia, pero no permite que el desorden en los hechos que has podido realizar jugando, afecten al resultado final, por lo que no puedes realizar tu propio discurso histórico. 
Los momentos de juego se encuentran flanqueados de inicio a fin por una narrativa que obliga a respetar el suceso según es conocido.

\section{Novedad teórico metodológica}

La novedad teórica y metodológica que incorporamos en este estudio radica en agregar o sumar dos disciplinas históricas a la línea ya planteada por los gamestudies; la iconografía y la arqueología, principalmente aplicada al estudio de las representaciones contemporáneas de las culturas mesoamericanas. Por otra parte, y obligados por la propia esencia del videojuego nos adentramos en las posibilidades de aprendizaje de la historia debido a la obligatoria inmersión en el período representado debido a la interactividad. Otra dimensión que abordamos, también heredada de que el videojuego no es otra cosa que un producto de consumo es el matiz de este tipo de productos de carácter histórico como parte de la cultura visual y, por lo tanto, de representarnos y asumir otras culturas o momentos del pasado.

La práctica lúdica permite al usuario inmiscuirse en las circunstancias de culturas ya desaparecidas con una libertad que sólo los desarrolladores han establecido, pero que cada vez es más inabarcable.

\section{La Campaña de Moctezuma}

Las campañas se encuentran embutidas en narrativas cinemáticas que conducen la historia. A modo de cómic, los escenarios a jugar se emparedan en narraciones que obligan que el proceso histórico sea el correcto.

En el caso de la Campaña de Moctezuma, la asesoría corrió a cargo del diseñador, biólogo y experto en estrategia Bruce Shelley (Universidad Syracuse y la Universidad del Estado de Nueva York) y con el equipo de desarrollo artístico de Ensemble Studios, y utilizando un viejo recurso cinematográfico, la voz en off, es narrado en primera persona por el actor mexicano Julio César Cedillo, conocido por sus papeles en Sicario (2005), Los tres entierros de Melquiades Estrada (2005) y La niebla (2007).

En estas narraciones comprobamos que los ingredientes que la componen no escapan del mito histórico, representando de forma cronológica los aspectos fundamentales de los hechos según la tradición historiográfica y cuya marca sigue en algunos casos presente en la actualidad. Así, como veremos a continuación, la traición de los tlaxcaltecas, los presagios que anunciaban la llegada del dios Quetzalcoatl o el temor de Moctezuma siguen presentes, aunque contrastan con el empirismo del

\begin{tabular}{|c|c|c|}
\hline Narración 1 & Objetivos del juego & Narración 2 \\
\hline $\begin{array}{l}\text { 1. Reinado sangriento } \\
\text { Presagios/sacrificios/llegada de } \\
\text { Quetzalcóatl }\end{array}$ & $\begin{array}{l}\text { Captura los cuatro templos } \\
\text { consagrados a Quetzalcóatl }\end{array}$ & $\begin{array}{l}\text { Derrota de los xochimilcos y } \\
\quad \text { Tlatelolcas/Prisioneros/Presagios }\end{array}$ \\
\hline $\begin{array}{l}\text { 2. La Triple Alianza } \\
\text { Presagios/Incendio templo } \\
\text { Huizilipochtli/triple alianza } \\
\text { ataca a tlaxcltecas }\end{array}$ & $\begin{array}{l}\text { Derrotar a los tlaxcaltecas } \\
\text { destruyendo sus centros } \\
\text { urbanos }\end{array}$ & $\begin{array}{l}\text { Primeras descripciones de los } \\
\text { españoles/lmpresión por barcos } \\
\text { y caballos/Moctezuma le envía } \\
\text { regalos. }\end{array}$ \\
\hline $\begin{array}{l}\text { 3. Quetzalcóatl } \\
\text { Lago hirviendo/Encuentro entre dos } \\
\text { mundos/Alianza entre } \\
\text { españoles y tlaxcaltecas }\end{array}$ & $\begin{array}{l}\text { derrota a los tlaxcaltecas, ayudar a } \\
\text { los aliados de Tabasco y } \\
\text { derrotar a los españoles. }\end{array}$ & $\begin{array}{l}\text { Derrota azteca/Moctezuma envía } \\
\text { más regalos/Cortés entra en } \\
\text { Tenochtitlán invitado por } \\
\text { Moctezuma }\end{array}$ \\
\hline $\begin{array}{l}\text { 4. La Noche Triste } \\
\text { La Llorona/dudas sobre la divinidad } \\
\text { de los españoles/Ambición de } \\
\text { oro/Asesinato de los sacerdotes } \\
\text { y destrucción de ídolos }\end{array}$ & $\begin{array}{l}\text { derrota a los tlaxcaltecas y los } \\
\text { españoles }\end{array}$ & $\begin{array}{l}\text { La noche triste/Tenochtitlán } \\
\text { destruída/Moctezuma muerto/ } \\
\text { Cuauhtémoc nuevo emperador }\end{array}$ \\
\hline $\begin{array}{l}\text { 5. El lago en ebullición } \\
\text { Cuauhtémoc dirige el ataque contra } \\
\text { españoles/Españoles se hunden } \\
\text { con el oro robado/Huída zona } \\
\text { norte del lago Texcoco. }\end{array}$ & $\begin{array}{l}\text { Derrotar a los tlaxcaltecas y a los } \\
\quad \text { españoles }\end{array}$ & $\begin{array}{l}\text { Reconstruir la } \\
\text { ciudad/Sacrificios/Viruela }\end{array}$ \\
\hline $\begin{array}{l}\text { 6. Lanzas rotas } \\
\text { Ataque de los } \\
\text { españoles/Organización de la } \\
\text { defensa/Resistencia azteca }\end{array}$ & Derrotar a españoles y tlaxcaltecas. & $\begin{array}{l}\text { Tenochtitlán destruído/Traición de } \\
\text { la triple alianza/Tenochtitlán } \\
\text { algún día reconstruída }\end{array}$ \\
\hline
\end{tabular}

Tabla 1. Narrativa y objetivos de la campaña de Moctezuma 


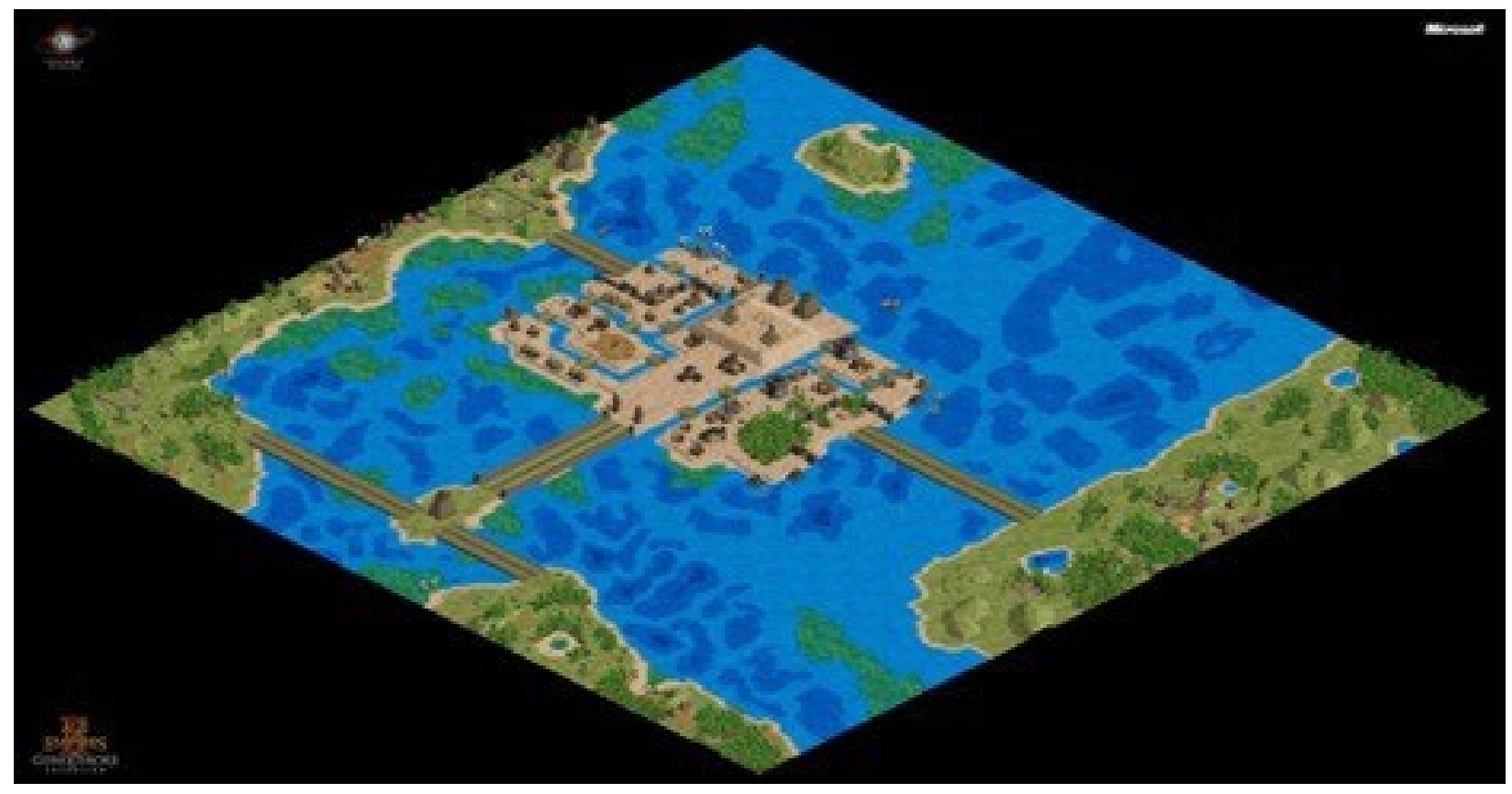

Ilustración 3 Mapa de Tenochtitlán para el escenario "La noche triste". La isla toma como modelo de la ciudad el mapa que acompañaba a las copias de la cartas de Hernán Cortés a Carlos Vy que fueron publicadas en Nuremberg en 1524.

narrador que, a todas luces, se atropella en el tiempo en elucubraciones considerablemente lejanas a la realidad mexica.

Las etapas que componen la Campaña de Moctezuma son seis:

1. Reinado sangriento

2. La Triple Alianza

3. Quetzalcóatl

4. La Noche Triste

5. El lago en ebullición

6. Lanzas rotas

En estas narraciones comprobamos que los ingredientes que la componen no escapan del mito histórico, representando de forma cronológica los aspectos fundamentales de los hechos narrados por Bernal Díaz del Castillo (1575) y Hernán Cortés (1524) que culminarán con las dos grandes obras de concepción decimonónica como son la de Prescott (1843) y Gibson (1978) y Thomas (1993), estas tres últimas más distribuidas en el ámbito anglosajón.

Así, como veremos a continuación, la traición de los tlaxcaltecas, los presagios que anunciaban la llegada de Quetzalcoatl o el temor de Moctezuma siguen presentes, aunque contrastan con el empirismo del narrador que, a todas luces, se atropella en el tiempo en elucubraciones considerablemente lejanas a la realidad mexica.
En la narrativa se hacen una serie de referencias que sugieren que otra obra ha sido tomada en cuenta para el hilo conductor de la historia como es la Visión de los Vencidos de Miguel León Portilla (1978) del cual se desprenden los Cantos Tristes de la Conquista. En cualquier caso,es una historia conocida por el gran público y que no recoge los modelos más recientes de Restall y la llamada Nueva Historia de la Conquista de América (2012)

La narrativa más tradicional se observa en todo el juego con las menciones a las torres sobre el mar, los presagios, la llorona ... es decir, todo aquello aceptado comúmente como una realidad histórica previa a los eventos de la Conquista. Los estudios históricos actuales consideran que dichas historias se construyeron en el momento posterior a la caída de México -Tenochititla y no antes (Aimi 2009).

En términos generales el juego sigue la dinámica básica de Age of Empires pero con algunas licencias "históricas" tal vez derivado de la narrativa del propio juego (el protagonista Cuauhtemoc como sobrino y no primo de Moctezuma II y el "olvido " de Cuitláhuac). Pero el juego muestra otras situaciones discordantes con la narrativa histórica e historiográfica. Desde un punto de vista histórico no tiene ningún sentido clasificar a los aztecas como un juego de la Edad Feudal idea que no responde ni a la estructura sociopolítica ni temporal de los aztecas. Lo 


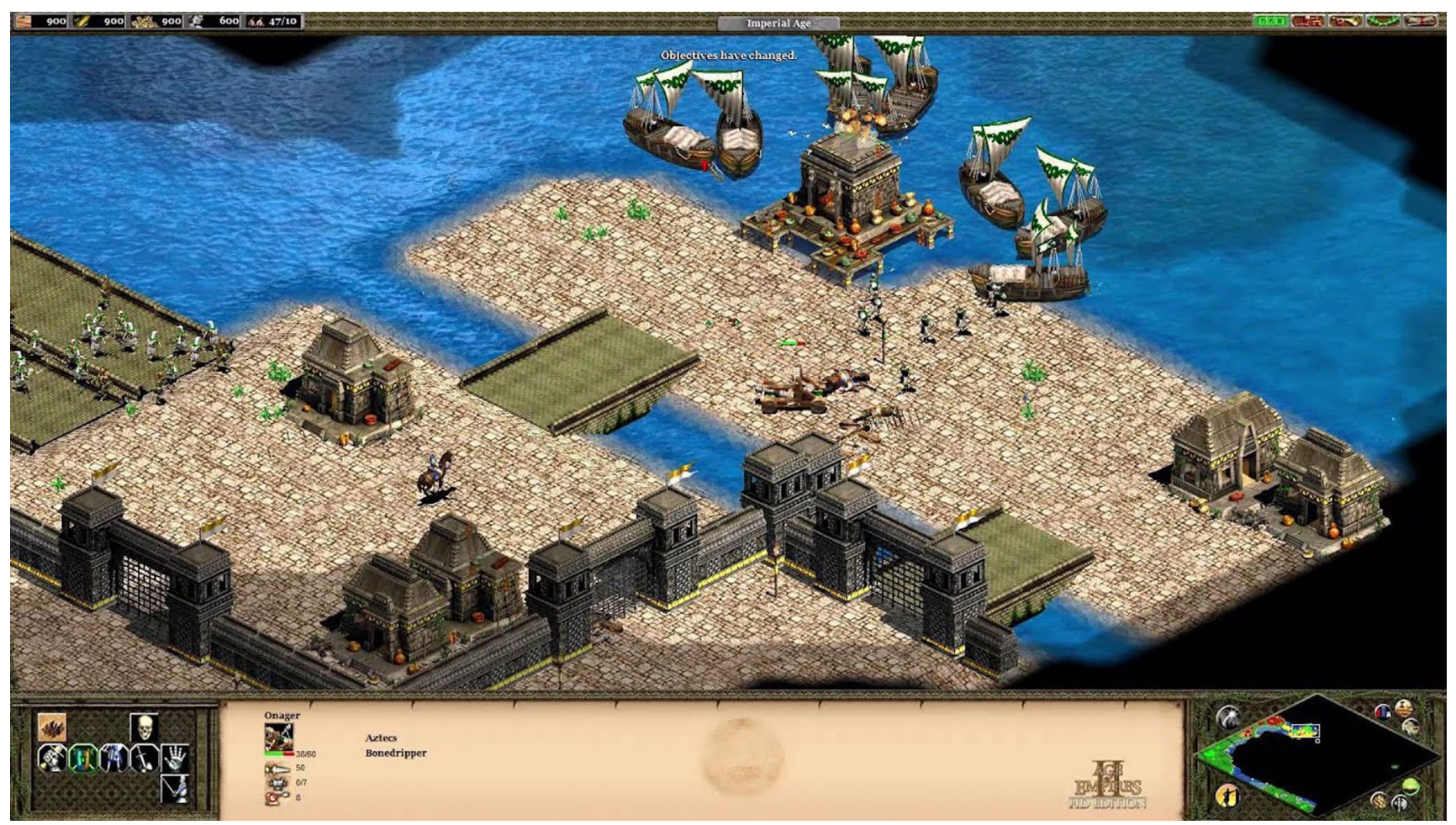

Ilustración 4 Ataque a Tenochtitlán. Un escenario construido poco factible de que corresponda a algo medianamente mesoamericano.

mismo sucede con la dinámica de Edad Imperial que presupone unos criterios de evolución sociopolítica de corte europeo que no encajan bien con los modelos propios de las culturas prehispánicas. Se puede comprender en términos de la propia dinámica del juego; el jugador ha de evolucionar y pasar de un estadío a otro pero no tiene nada que ver con los modelos sociopolíticos mesoamericanos. En el entendido de que la periodizaciones son construcciones hechas por historiadores y/o arqueólogos, los aztecas se deberían encuadrar en el Posclásico tardío (1200-1521) y bajo un modelo de sociedades estatales hegemónicas. En el caso mexica estamos hablando de una monarquía electiva como sistema de gobierno. Los errores continúan al clasificar a los Tepenacas o Tepanecas, Texcocanos y Xochimilcas como mayas cuando se refieren a pueblos de origen chichimeca (Tepenacas), Acolhuas (Texcoco) y Xochimilcas (de origen incierto pero de tradición del Altiplano Central) que se encontraban instalados en la Cuenca de México desde el siglo IX hasta el XVI.

Desde un punto de vista iconográfico, el videojuego se desarrolla en un ambiente selvático o lacustre según la escena. Como elementos esenciales va a retomar la imagen que recoge las unidades más reconocibles del imperio azteca, como son los guerreros águila y los sacerdotes —el resto de las unidades, aldeanos, arqueros... son para todas las civilizaciones de igual forma aunque de distinto color - y los edificios más emblemáticos de la cultura mexica. Como edificio principal, que en el videojuego es denominado "maravilla" representando ésta la última etapa de desarrollo constructivo de esta civilización sería el Templo Mayor, la imagen más icónica de los mexicas junto a la piedra del sol. Los referentes utilizados sin embargo también aúnan otros elementos reconocibles como el Palacio de Palenque y algunos elementos someramente inspirados en la iconografía de Quetzalcoatl (Ilustración 5).

\section{A modo de conclusión}

La introducción de cualquier tecnología a la enseñanza es difícil, y más aún que penetre en los círculos académicos y genere un debate. La historia de las invenciones está plagada de episodios donde la reticencia de los círculos universitarios a aceptar los elementos que van a caracerizar los nuevos tiempos ha retrasado elementos fundamentales para el desarrollo científico y cultural. De todos es conocido el miedo a la perdida de la memoria que podría devenir por la palabra impresa, el miedo a la desaparición de las relaciones personales por la invención 


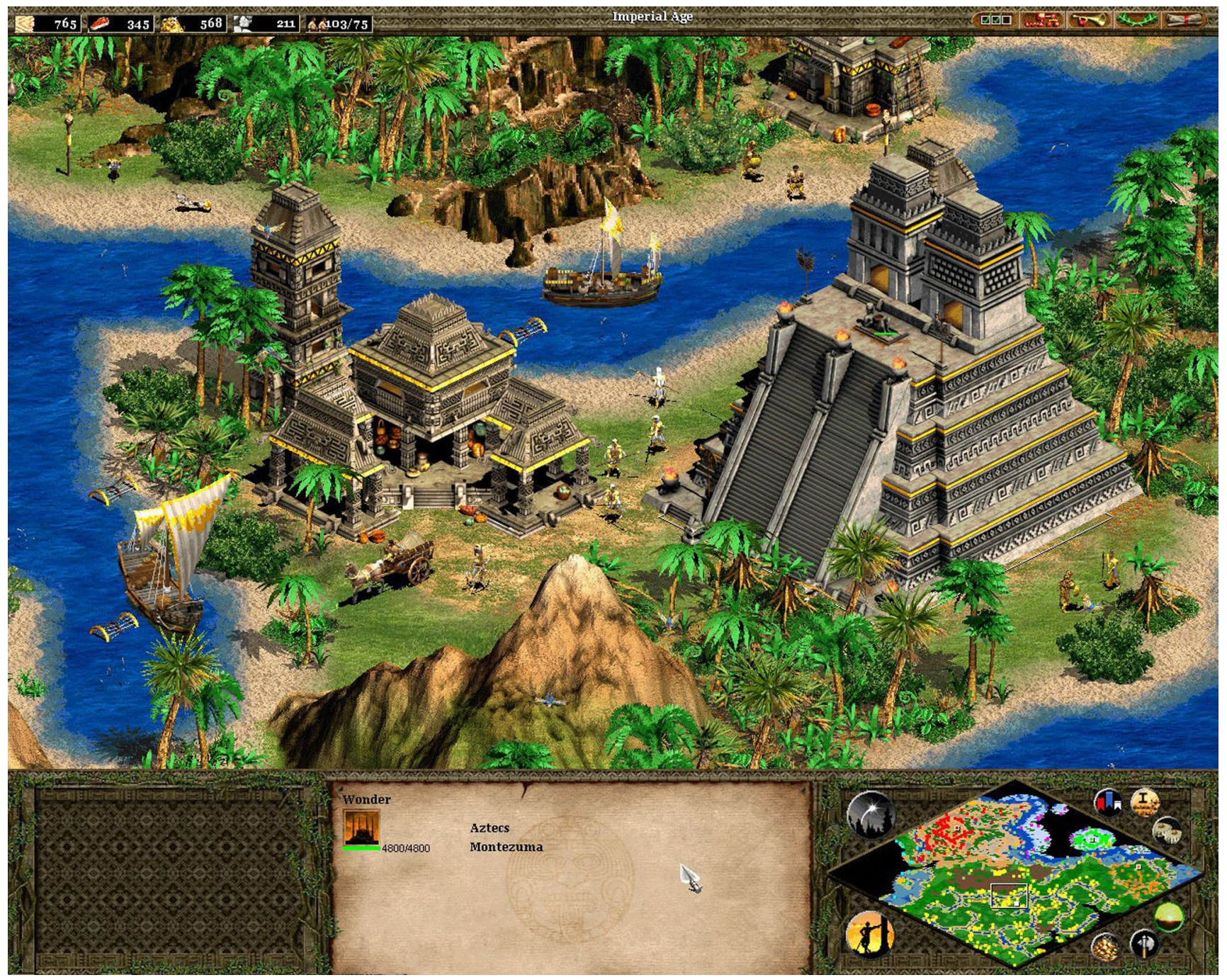

Ilustración 5 Maravilla azteca. El Templo Mayorde de nuevo acompañada de un conjunto con torre que recuerda al palacio de Palenque. Dejamos a parte el detalle de los carros y las naves con velas latinas.

del teléfono o la crisis de la pintura que supuso la aparición de la fotografía.

Actualmente nos encontramos con una tecnología que ha ocupado la casi la totalidad de nuestra atención diaria, pantallas ocupan casi todos nuestros quehaceres, y se han vuelto cotidianas y accesibles.

Lo más atractivo de la computación, y la industria de mayor crecimiento y calado es la de los videojuegos, donde lo que la población occidental invierte una gran cantidad de tiempo. Como historiadores, esta realidad no puede resultarnos ajena, ya que es el ecosistema habitual donde la sociedad se mueve y un mundo habitual entre los alumnos a los que impartimos clase.

La realidad está ahí y la única posibilidad es aliarnos con ella aprovechando las posibilidades que nos da. Si bien el videojuego ha suscitado polémicas como que incita a la violencia, los estudios han demostrado que no hay una relación entre este entretenimiento y la tendencia a la agresión. Superados estos escollos que, como ya apuntábamos, achacan a cualquier tipo de tecnología, debemos adentrarnos en ese mundo para, a modo de curadores, sacar el mayor rendimiento de los mismos.

Dentro de los videojuegos de temática histórica nos encontramos con un caso que va a reforzar la forma de ver el mundo mexica, el Age of Empire II: The Conqueror que, a pesar de los evidentes errores y la continuidad de la generación de estereotipos puede ayudar al conocimiento de esta cultura.

Las posibilidades de expansión de una idea o una imagen que dan estos productos se escapa a nuestras 
posibilidades de catalogación o análisis. Un videojuego como éste, distribuído por Microsoft llegará a cualquier parte del mundo donde exista una computadora con un mínimo de recursos. Por su manufactura, el producto va a reproducir fielmente la narración estereotipada de la conquista de Tenochtitlán y va a enseñar una recreación del mundo mexica que, a parte de mantener las consabidas imágenes, a veces confundidas, de los edificios más emblemáticos de esa cultura, o de los atuendos y ambientes naturales, las va a arraigar debido a las capacidades sugestivas que da la interactividad (Venegas Ramos, 2013).

Si bien tarde, la academia ha dado cuenta del potencial de estos productos y ha construído nuevas líneas de investigación que incluyen el estudio de la historia a través del videojuego, curas con aplicaciones específicas para enfermedades mentales o serious game que nos meten en la piel de un refugiado. El universo del videojuego lo ha ocupado todo, tanto en la temática como en la experiencia.

El hecho de estudiar estos medios y su repercusión en la sociedad y en la investigación nos sitúa ante un reto que poco a poco va tomando forma. Los iniciales game studies han ido abriéndose a la transdisciplinariedad hasta ser tenidos en cuenta en campos tan dispares como la medicina, la estética o la arqueología, aunque, en muchos casos, como el que nos ocupa, es necesario abrir un nuevo campo nuevo a nivel metodológico.

No tan sólo esto. En una sociedad dinámica que implementa constantemente nuevas tecnologías que hacen énfasis en los instrumental, la reflexión de estos nuevos elementos compete dentro del campo de la universidad y centros de investigación. Un juego puede llegar a ser más exitoso y trascendente dentro de la docencia y la generación de un espíritu crítico si llegamos antes a reflexionar sobre los mismos. Asimismo nos ofrecen la oportunidad de dialogar con estos nuevos elementos y contribuir con nuevos productos culturales que involucren elementos de reflexión histórica y con cocimiento empírico del pasado. Como se dicen vulgarmente: convertir una posible amenaza a una distorsión del pasado prehispánico a una oportunidad para dar a conocer una realidad muchas veces disfrazada de exotismo y no de conocimiento. La dinámica de este tipo de juegos nos permite incidir en los procesos históricos, teorías de pensamiento que bien utilizados pueden ayudar al estudiante a la asumpción de aquellos temas que se presentan a veces un poco áridos. Y como no la posibilidad de generar juegos educativos y lúdicos en el ámbito docente universitario.

\section{Bibliografía}

AIMI, Antonio., 2009. La verdadera visión de los vencidos: la conquista de México en las fuentes aztecas. Universidad de Alicante, Alicante.

BETTNER, P., \& TERRANO, M., 2001. 1500 archers on a 28.8: Network programming in Age of Empires and beyond. Presented at GDC2001, 2, 30p.

CORTÉS, Hernán., 1922. Cartas de relación de la conquista de Méjico. Editorial Calpe, Madrid.

DEL CASTILLO, Bernal Díaz., 2010. Historia verdadera de la conquista de la Nueva España. Cambridge University Press, Cambridge.

EVANS, R. J., 2018. Contrafactuales. ¿Y si todo hubiera sido diferente?. Turner, Madrid.

FERGUSON, N., 1998. Historia virtual ¿qué hubiera pasado si ...? Taurus, Madrid.

FRASCA, G., 1999. Ludology meets Narratology: Similitude and differences between (video)games and narrative. Parnasso 3: 365-367.

GIBSON, Charles. 1978. Los aztecas bajo el dominio español (1519-1810). Siglo xxi, 1978.

GREIMAS, Julien Algirdas, 1971. Semántica estructural: investigación metodológica. Editorial Gredos, Barcelona.

HUIZINGA, Johan, 2007. Homo ludens. Alianza, Madrid.

JIMÉNEZ ALCÁZAR, J. F., 2009. Video games and the Middle Ages, Imago Temporis 3, 311-365.

JIMÉNEZ ALCÁZAR, J. F., 2011. The other possible past: simulation of the Middle Ages in video games, Imago Temporis 5, 171-199.

JIMÉNEZ ALCÁZAR, J. F. y RODRÍGUEZ, G. F., 2015. Entre la huida y el seguimiento. Monstruos como modelos iconográficos de la Edad Media a través de los videojuegos. En C. San Nicolás, M.Á. Nicolás (Comps.), Videojuegos y sociedad digital: nuevas realidades de estudio para la percepción del pasado histórico, 11-39), Universidad Nacional de Mar del Plata, Mar del Plata, 11-39.

JIMÉNEZ ALCÁZAR, Juan Francisco, 2018. «La historia no fue así»: reflexiones sobre el fenómeno de la historia contrafáctica en los videojuegos históricos. Clío. History and History Teaching 44.

LEÓN-PORTILLA, Miguel, 2008. Visión de los vencidos. Universidad Nacional Autónoma de México, México.

PELEGRÍN CAMPO, J., 2010. La historia alternativa como herramienta didáctica: una revisión historiográfica, Clío. History and History Teaching 36.

PRESCOTT, William H., 1968, Historia de la conquista de México. Mercurio, Madrid.

RESTALL, Mathew, 2004. Los siete mitos de la conquista española. Ediciones Paidós Ibérica, Barcelona.

VENEGAS RAMOS, A., 2013. La contrafactualidad de los videojuegos, Zehngames 13 noviembre 2013. 